\title{
(2) OPEN ACCESS \\ Uncommon but imperative cause of repeated acute stent thrombosis: Kounis syndrome type III
}

\author{
Shiro Miura (1) , ${ }^{1}$ Takehiro Yamashita, ${ }^{1}$ Masaki Murata, ${ }^{2}$ Nicholas G Kounis ${ }^{3}{ }^{3}$
}

'Department of Cardiology, Hokkaido Ono Memorial Hospital, Sapporo, Japan ${ }^{2}$ Department of Surgical Pathology, Hokkaido Ohno Memorial Hospital, Sapporo, Japan

${ }^{3}$ Department of Cardiology, University of Patras School of Medicine, Patras, Greece

Correspondence to Dr Shiro Miura; shirotan1027m@yahoo.co.jp

Accepted 4 February 2021

Check for updates

(C) BMJ Publishing Group Limited 2021. Re-use permitted under CC BY-NC. No commercial re-use. See rights and permissions. Published by BMJ.

To cite: Miura S, Yamashita T, Murata M, et al. BMJ Case Rep 2021;14:e240704. doi:10.1136/bcr-2020240704

\section{SUMMARY}

A 69-year-old woman with a history of allergic reactions to unknown metals who presented 1 year prior with acute coronary syndrome complicated by acute stent thrombosis (ST) was admitted due to new-onset chest pain during mild exercise. She electively underwent coronary angiography, revealing a newly developed stenosis in the fourth branch of the posterior descending artery, treated with an everolimus-eluting stent. One hour later, she reported of sudden chest tightness and nausea; ECG revealed significant ST-segment elevation in the II, III and aVF leads. We suspected ST-segment elevation myocardial infarction resulting from an allergic reaction (ie, Kounis syndrome type III) and managed it properly by eliminating other potential causes. The tentative diagnosis was confirmed by pathological examination of aspirated materials. Kounis syndrome type III may be a frequently undiagnosed clinical entity, emphasising the importance of pathological examination of aspirated materials when implanting coronary stents and history-taking of allergies to stent metals.

\section{BACKGROUND}

The Kounis syndrome was first reported in 1991 as an acute coronary syndrome, including coronary spasm (type I), atheromatous plaque erosion or rupture (type II) and stent thrombosis (ST) (type III), resulting from allergic or hypersensitivity reactions, or anaphylactic or anaphylactoid insults. ${ }^{1}$ In type III, all three components of drug-eluting stents (stent metals, polymers and eluted drugs) could be responsible for inducing allergic reactions and ST. ${ }^{2}$ To make an accurate diagnosis of Kounis syndrome type III, an urgent aspiration of intrastent thrombus, followed by histological examination of aspirated material and staining for eosinophils (H\&E) and mast cells (Giemsa) can be mandatory. ${ }^{3}$ Concerning this point, Kounis syndrome type III may not be an uncommon disease but an infrequently misdiagnosed entity, which, however, has clinical significance because of the wide range of triggers and possible fatal consequences, unless promptly recognised. Herein, we report a novel case of repeated acute ST following a local allergic reaction diagnosed that was managed properly in a patient with a history of metal allergy.

\section{CASE PRESENTATION}

A 69-year-old woman with a medical history of hypertension was admitted to our heart centre with symptoms of chest pain during exercise. Mild allergic reactions to unknown metals were reported 30 years prior but had not been investigated further. Her medical history was noteworthy for acute coronary syndrome, 1 year before admission, complicated by acute ST in the proximal left anterior descending artery (LAD). This occurred 1 hour (figure $1 \mathrm{~A}$ ) after the primary percutaneous coronary intervention (PCI) with a $2.5 \times 26 \mathrm{~mm}$ zotarolimuseluting stent (Resolute Onyx; Medtronic, Santa Rosa, California, USA) under the guidance of intravascular ultrasound (IVUS).

After admission, she electively underwent coronary angiography (CAG) on hospital day 2 to determine the cause of her chest pain. CAG revealed no in-stent restenosis in the proximal LAD (figure 1B) and critical stenosis in the fourth branch of the posterior descending artery (figure 1C). To treat the stenosis, which was thought to be the culprit lesion for her angina, a $2.25 \times 38 \mathrm{~mm}$ everolimus-eluting stent (XIENCE Sierra; Abbott Vascular, Santa Clara, California, USA) was implanted (figure 2A,B) the same day. Aspirin (100 mg) and clopidogrel (75 mg) were administered daily as maintenance treatment 7 days prior to implantation. An IVUS (AltaView; Terumo Corporation, Tokyo, Japan) was performed to optimise the stenting by probing that no stent complications such as under-expansion, malposition or stent fracture were observed (figure 2C,D). One hour after the final angiogram, the patient reported of sudden chest tightness and nausea. There was no generalised itching or cutaneous erythema, and her vital signs were as follows: blood pressure, 173/86 $\mathrm{mm} \mathrm{Hg}$; heart rate, 76 beats/min and oxygen saturation, 98\%. An ECG revealed significant ST-segment elevation in the II, III and aVF leads (figure 3).

\section{DIFFERENTIAL DIAGNOSIS}

ST-segment elevation myocardial infarction/acute stent thrombosis resulting from

- Procedure related (stent under-expansion, incomplete stent apposition and coronary artery dissection).

- Kounis syndrome (type III).

- Heparin-induced thrombocytopenia (HIT).

- Clopidogrel resistance.

- Plasma factors influencing the thrombophilic propensity (protein $\mathrm{C}$, protein $\mathrm{S}$, antithrombin III, activated protein C, antiphospholipid antibodies and anticardiolipin antibodies, etc).

\section{TREATMENT}

We suspected ST-segment elevation myocardial infarction resulting from an allergic reaction (ie, Kounis syndrome type III). Intravenous hydrocortisone $(125 \mathrm{mg})$, oxygen and saline were immediately administered. Emergent CAG confirmed a 


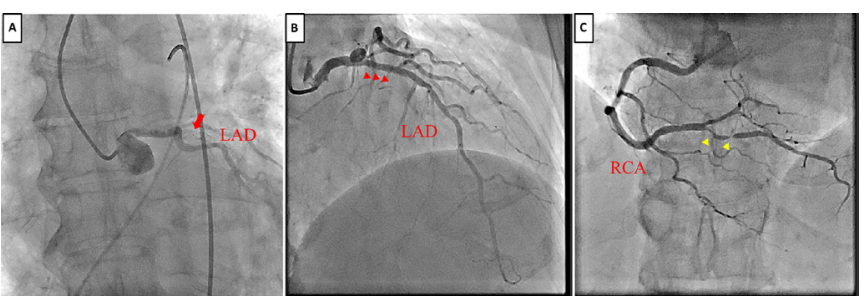

Figure 1 Coronary artery angiography. (A) Acute stent thrombosis of the left anterior descending coronary artery (LAD) following implantation of a stent (red arrow) 1 year prior. (B) Left coronary artery angiography without signs of restenosis (red arrow heads) in the proximal LAD where the acute stent thrombosis had developed 1 year prior. (C) Tight stenotic lesions (yellow arrowheads) in the distal right coronary artery (RCA) are noted.

thrombotic semi-occlusion of the stent site (figure 2E). Optical frequency domain imaging (OFDI) (LUNAWAVE, Terumo Corporation, Tokyo, Japan) revealed a residual thrombus overlying the stent struts (figure 2F,G). Aspiration thrombectomy and subsequent balloon angioplasty with a $3 \mathrm{~mm}$ non-compliant balloon were performed, which resulted in an improvement from thrombolysis in myocardial infarction (TIMI) flow grade 1-2 (figure 4A). The intra-aortic balloon was left in place for 3 days, during which time the TIMI flow grade in the right coronary artery was 3 , as determined via CAG (figure 4B).

\section{INVESTIGATIONS}

After the bailout procedure, the peak troponin I and creatine kinase-MB levels were $27.8 \mathrm{pg} / \mathrm{mL}$ and $73.7 \mathrm{U} / \mathrm{L}$, respectively. The lowest platelet count after thrombectomy and angiography was $180 \times 10^{9} / \mathrm{L}$ (initial platelet count, $195 \times 10^{9} / \mathrm{L}$ ). The blood eosinophil percentage was $0.5 \%$ at 5 hours after the onset. As we suspected clopidogrel resistance, we replaced clopidogrel with

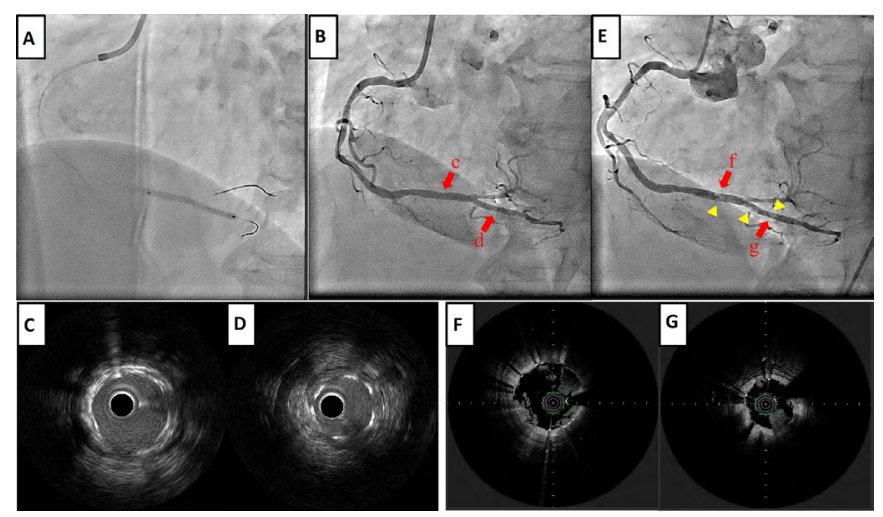

Figure 2 Elective percutaneous coronary intervention and intracoronary imaging findings. (A) A drug-eluting stent $(2.25 \times 38 \mathrm{~mm})$ was deployed in the distal right coronary artery; the kissing balloon technique was not employed. (B) Stent placement provided excellent results in the final angiogram. The red arrows denote the areas shown in panels C and D, respectively. (C, D) Intravascular ultrasound imaging confirmed optimal stent expansion in the distal right coronary artery $\left(C_{t}\right.$ stent proximal; D, stent distal). (E) One hour after the final angiogram, angiographic appearance of multiple thrombi in the stent (yellow arrowheads) is noted. The red arrows denote the areas shown in panels $F$ and $G$, respectively. $(F, G)$ Optical frequency domain imaging confirming the presence of the thrombus mainly in the proximal $(F)$ and distal $(G)$ regions of the implanted stent.

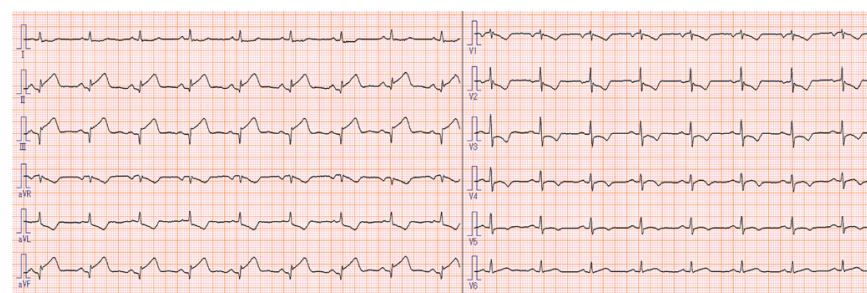

Figure 3 ECG during the stent thrombosis (ST) event showing STsegment elevation in leads II, III and aVF and ST-segment depression in leads V $1-3$, I and aVL.

prasugrel (20 $\mathrm{mg}$ as the loading dose, followed by $3.75 \mathrm{mg}$ as the maintenance dose) during the bailout PCI.

Pathological examination of the thrombotic aspirate (figure 5A) revealed platelet aggregates, fibrin and white cells, including eosinophils and neutrophils (figure 5B); mast cells were not detected (figure 5C). CYP2C19*2 and CYP2C19*3 genotyping via polymerase chain reaction-restriction fragment length polymorphism analysis revealed that the patient was an intermediate metaboliser (CYP2C19*1/*3 genotype). The activities of protein $\mathrm{C}$, protein $\mathrm{S}$, antithrombin III, activated protein $\mathrm{C}$ and $\alpha 2$-antiplasmin were within normal limits according to haematological tests. Antiphospholipid and anticardiolipin antibodies were negative. The above-mentioned findings were compatible with acute ST due to an allergic reaction. A patch test for metal allergies was strongly positive for nickel and cobalt, which are the main components of the patient's two implanted coronary stents.

\section{OUTCOME AND FOLLOW-UP}

The patient's clinical course was uneventful afterward, and she was discharged on hospital day 12 and had no symptoms at the 3-month follow-up visit.

\section{DISCUSSION}

Type III Kounis syndrome is defined as ST with eosinophils and mast cells in the aspirated thrombus. ${ }^{2}$ The lack of mast cells in our patient's thrombotic material may have been due to the very short period between symptom onset and aspiration. In most previously reported cases with mast cells observed in implanted stent sites, histological analyses were performed several hours after the event or even during the autopsy. ${ }^{4}$ All components of drug-eluting coronary stents can potentially cause allergic reactions and Kounis syndrome type III along with possibly concomitant oral antiplatelet drugs and environmental exposures. ${ }^{2}$ Our patient had a positive allergic patch test response to nickel and

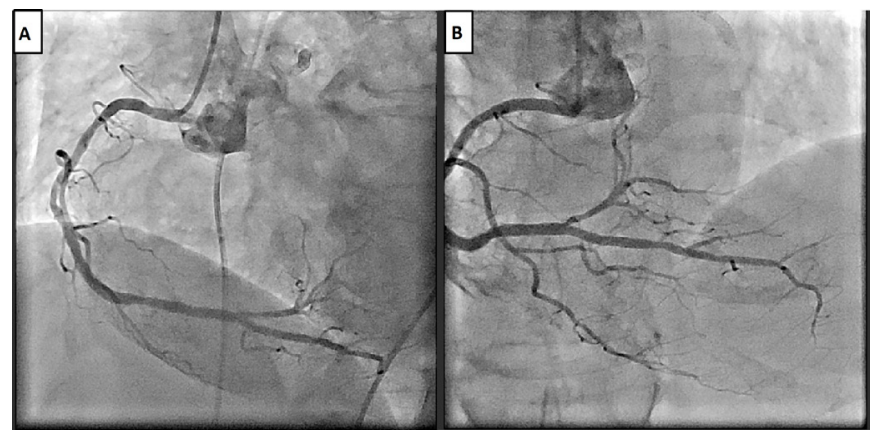

Figure 4 Final angiogram after thrombus aspiration and balloon angioplasty (A). Absence of the thrombus in the distal right coronary artery following a 3-day use of the intra-aortic balloon pump (B). 


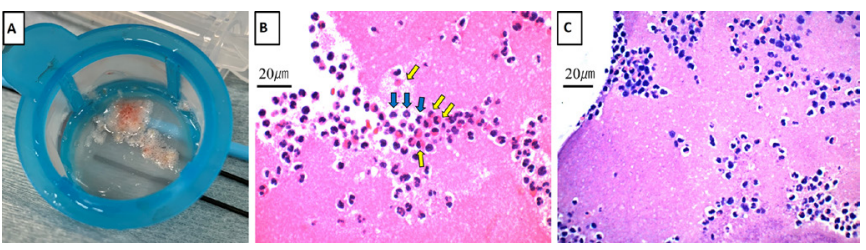

Figure 5 (A) Thrombotic material is aspirated from the right coronary artery. (B) The aspirate consists of platelet aggregates, fibrin and white cells, including eosinophils (yellow arrows) and neutrophils (blue arrows). H\&E. (C) Mast cells are not present in the aspirate-Giemsa stain.

cobalt, which are the two main components of two different stents (everolimus-eluting and zotarolimus-eluting stents) that were implanted separately. Hence, hypersensitivity to these metals likely accounted for her apparent repeated acute ST. ${ }^{5}$ Notably, her clinical course included focal hypersensitivity to the coronary stent that resulted in acute ST immediately following stent implantation. Less commonly, she did not demonstrate typical systemic allergic reactions, such as skin itching, pruritus, dyspnoea, and hypotension. ${ }^{6}$

The mechanisms underlying ST are multifactorial. Before concluding acute ST resulting from allergic reactions after the implantation of drug-eluting stents, we should explore other potential mechanisms, such as patient-related, procedural and postprocedural factors (including type and duration of antiplatelet therapy) as discussed previously. ${ }^{4}$ In our case, procedural factors, such as stent under-expansion, incomplete apposition and fracture, were unlikely to cause acute ST because the procedure was carefully performed via IVUS guidance and we also safely confirmed that these stent-related causes were much less likely via OFDI during the bailout PCI. HIT was a differential diagnosis if the patient administered heparin presented with thrombocytopenia or thrombosis. While the platelet count in this patient was within the normal limit and the relative change in platelets was not definitive to diagnose HIT, although the HIT

\section{Patient's perspective}

I am greatly engaged and interested in this clinical research of this especially unusual but important medical problem that I was suffering from. This novel report could hopefully contribute not only to improve my health condition in the future but also to deepen the understanding of the Kounis syndrome, leading to the further development of specific treatments for this clinical entity.

\section{Learning points}

Kounis syndrome is an acute coronary syndrome caused by an allergic reaction to various drugs or substances.

- Kounis syndrome type III may be a frequently undiagnosed clinical entity when implanting coronary stents.

- Kounis syndrome type III warrants careful consideration, emphasising the importance of pathological examination of aspirated materials and history-taking of previous allergic reactions to stent metals. test showed a weakly positive reaction. Similarly, plasma factors influencing the thrombophilic propensity, such as protein C, protein S, antithrombin III, activated protein C, antiphospholipid antibodies and anticardiolipin antibodies, were all within the normal range. Clopidogrel resistance is associated with subacute $\mathrm{ST}^{7}$ We immediately switched $75 \mathrm{mg}$ of clopidogrel to $3.75 \mathrm{mg}$ of prasugrel, a third generation thienopyridine agent with greater platelet inhibition, and later, the patient disclosed not carrying CYP2C19 loss of-function alleles, which are seen more frequently in Japanese population. ${ }^{8}$ Overall, the abovementioned findings were compatible with acute repeated ST due to an allergic reaction.

To the best of our knowledge, this is the first report of repetitive acute ST induced by an allergic reaction, highlighting eosinophilic infiltration in the aspirated thrombus on pathological examination. Using intradermal skin tests, we identified nickel and cobalt as the causes of the allergic reaction and consequent Kounis syndrome. Herein, this novel case conveys a significant message that Kounis syndrome type III should be considered when implanting coronary stents. Rather than being a rare disease, Kounis syndrome type III is a frequently undiagnosed clinical entity. Hence, we emphasise the importance of the pathological examination of aspirated materials and historytaking of previous allergic reactions to stent metals in cases of idiopathic ST.

Contributors SM was involved in the case selection, the main manuscript writing and the collection of references. TY revised the manuscript critically for important intellectual content and gave the final approval for the version published. MM conducted pathological examinations. NGK supervised the case presentation and reviewed the entire manuscript.

Funding The authors have not declared a specific grant for this research from any funding agency in the public, commercial or not-for-profit sectors.

Competing interests None declared.

Patient consent for publication Obtained.

Provenance and peer review Not commissioned; externally peer reviewed.

Open access This is an open access article distributed in accordance with the Creative Commons Attribution Non Commercial (CC BY-NC 4.0) license, which permits others to distribute, remix, adapt, build upon this work non-commercially, and license their derivative works on different terms, provided the original work is properly cited and the use is non-commercial. See: http://creativecommons.org/ licenses/by-nc/4.0/.

\section{ORCID iDs}

Shiro Miura http://orcid.org/0000-0002-9634-5980

Nicholas G Kounis http://orcid.org/0000-0002-9751-6710

\section{REFERENCES}

1 Kounis NG, Zavras GM. Histamine-Induced coronary artery spasm: the concept of allergic angina. Br J Clin Pract 1991;45:121-8

2 Kounis NG. Kounis syndrome: an update on epidemiology, pathogenesis, diagnosis and therapeutic management. Clin Chem Lab Med 2016;54:1545-59.

3 Kounis NG. Coronary hypersensitivity disorder: the Kounis syndrome. Clin Ther 2013;35:563-71.

4 Chen JP, Hou D, Pendyala L, et al. Drug-Eluting stent thrombosis: the Kounis hypersensitivity-associated acute coronary syndrome revisited. JACC Cardiovasc Interv 2009;2:583-93.

5 Kirtane AJ, Stone GW. How to minimize stent thrombosis. Circulation 2011;124:1283-7.

6 Adachi $\mathrm{H}$, Ihara M, Nojima Y, et al. Kounis syndrome caused by anaphylaxis without skin manifestations after cefazolin administration. J Allergy Clin Immunol Pract 2019;7:317-9.

7 Mega JL, Close SL, Wiviott SD, et al. Cytochrome P-450 polymorphisms and response to clopidogrel. N Engl J Med 2009;360:354-62.

8 Jinnai T, Horiuchi H, Makiyama T, et al. Impact of CYP2C19 polymorphisms on the antiplatelet effect of clopidogrel in an actual clinical setting in Japan. Circ J 2009:73:1498-503 
Copyright 2021 BMJ Publishing Group. All rights reserved. For permission to reuse any of this content visit https://www.bmj.com/company/products-services/rights-and-licensing/permissions/

BMJ Case Report Fellows may re-use this article for personal use and teaching without any further permission.

Become a Fellow of BMJ Case Reports today and you can:

- Submit as many cases as you like

- Enjoy fast sympathetic peer review and rapid publication of accepted articles

- Access all the published articles

- Re-use any of the published material for personal use and teaching without further permission

Customer Service

If you have any further queries about your subscription, please contact our customer services team on +44 (0) 2071111105 or via email at support@bmj.com.

Visit casereports.bmj.com for more articles like this and to become a Fellow 